\title{
Information Systems Development Methodologies in Developing Higher Education
}

\author{
Adam Marks \\ Department of Business Administration, Embry-Riddle Aeronautical University, Daytona Beach, USA \\ Email: Marksa@erau.edu
}

Received December $12^{\text {th }}$, 2011; revised January $8^{\text {th }}, 2012$; accepted January $22^{\text {nd }}, 2012$

\begin{abstract}
Studies concerned with the status of Information Systems Development Methodologies usage in many developing countries including the factors that influence and motivate their use, current trends, difficulties, and barriers to adoption are lacking, especially within the higher education sector. This paper examines these identified gaps in a developing country, namely the United Arab Emirates. The initial findings reveal that there is limited knowledge and understanding of the concept of ISDM in federal higher education institutions in the UAE. This is reflected in the quality of the software products being developed and released. However, the analysed data also reveals a trend whereby federal higher education institutions in the UAE are gradually moving towards increased ISDM adoption and deployment.
\end{abstract}

Keywords: IS; ISDM; Methodology; Higher Education; UAE

\section{Introduction}

Despite the arguments about the usefulness of ISDM, ISDM are expected to be largely used in the current era more than ever before (Avison, 2003). A review of literature shows that there is insufficient empirical research on ISDM adoption. For instance, (Beynon-Davies \& Williams, 2003) state that there are "few studies that were conducted in order to identify how ISDM are selected or adapted, or how they are used.” A survey of prior studies of ISDM adoption shows clear differences between the number of studies of ISDM adoption that have been undertaken in developed and third/developing countries (Wynekoop \& Russo, 1997). None has been conducted in the UAE or the greater Middle East area.

The objective of this research is to investigate Information Systems Development Methodologies (ISDM) adoption in the federal higher education sector of a developing country, namely the United Arab Emirates (UAE). An empirical study was conducted by means of a survey, using a questionnaire and a number of face-to-face interviews with Information Systems (IS) managers in federal higher education institutions in the UAE, to empirically examine ISDM practices and ascertain the extent to which there was a need for an ISDM adoption model for these institutions. The survey was also intended to enable the testing of hypotheses formulated at an early stage of the research program. The Delphi method was undertaken to generate a confirmed list of ISDM adoption variables for decision making.

\section{Related Work}

Defining ISDM is not a simple task as there is no standard accepted definition (Husiman \& Iivari, 2002; Husiman \& Iivari, 2006). For instance, the British Computer Society (BCS) Information System Analysis and Design Working Group defined ISDM as "A recommended collection of philosophies, phases, rules, techniques, tools, documentation, management, and training for developers of information systems” (Avison \& Fitzgerald,
2006). Reference (Avison \& Fitzgerald, 2006) extended this definition as follows: "A recommended means to achieve the development, or part of the development, of information system based on a set of rationales and an underlying philosophy that support, justifies and makes coherent such a recommendation for a particular context". The recommended means usually includes the identification of phases, procedures, tasks, rules, techniques, guidelines, documentation and tools. They might also include recommendations concerning the management and organization of the approach and the identification and training of the participants.

In terms of ISDM classifications, various classifications of ISDM were identified in the literature such as those reported by (Iivari \& Huisman, 2001), and (Charvat, 2003). Reference (Beynon-Davies \& Williams, 2003) identified three major types of ISDM, including structured methodologies (e.g. SSADM), rapid application development (e.g. DSDM), and Object-oriented methodologies (e.g. RUP). Reference (Avison \& Fitzgerald, 2006) introduced a more comprehensive classification of ISDM as shown in Table 1.

ISDM adoption remains a controversial issue among many organizations (Fitzgerald, 1998), (Avison \& Fitzgerald, 2003). On the one hand, many practitioners view ISDM as the means for improving the quality of the information system development process and there are significant pressures to use ISDM as a requirement to obtain ISO certification or adhere to standards required by some governments. On the other hand, there are also considerable arguments against the use of ISDM, including 1) mismatches with organizational or Information Systems (IS) projects requirements; 2) ISDM vendor dependency; 3) system development delay; 4) system development stagnation (Fitzgerald, 1998). A review of literature shows that while some organizations claim that they use ISDM successfully with positive results and viewthem as an essential approach to improve the quality and to increase the productivity of the software development process, others argue about the benefit of using these 
Table 1.

Types of information systems development methodologies.

\begin{tabular}{|c|c|}
\hline Types of ISDM & Examples \\
\hline $\begin{array}{l}\text { Process-oriented } \\
\text { methodologies }\end{array}$ & $\begin{array}{l}\text { Structured analysis, design, and implementation } \\
\text { of information systems (STRADIS). } \\
\text { Yourdon system method (YSM). } \\
\text { Jackson system development (JSD). }\end{array}$ \\
\hline Blended methodologies & $\begin{array}{l}\text { Structured systems analysis and design method } \\
\text { (SSADM). } \\
\text { Information Engineering Methodology (IEM). }\end{array}$ \\
\hline $\begin{array}{l}\text { Object-oriented } \\
\text { methodologies }\end{array}$ & $\begin{array}{l}\text { Object Oriented Analysis and Design (OOA \& } \\
\text { D ) by Coad and Yourden. } \\
\text { Rational Unified Process (RUP). }\end{array}$ \\
\hline $\begin{array}{l}\text { Rapid development } \\
\text { methodologies }\end{array}$ & $\begin{array}{l}\text { Dynamic Systems Development Method (DSDM). } \\
\text { Extreme Programming (XP). } \\
\text { Web IS Development Methodology (WISDM). }\end{array}$ \\
\hline $\begin{array}{l}\text { People-oriented } \\
\text { methodologies }\end{array}$ & $\begin{array}{l}\text { Effective technical and human implementation } \\
\text { of computer-based systems (ETHICS). } \\
\text { KADS. }\end{array}$ \\
\hline $\begin{array}{l}\text { Organizational-oriented } \\
\text { methodologies }\end{array}$ & $\begin{array}{l}\text { Soft System Methodology (SSM) } \\
\text { Information system work and analysis of } \\
\text { changes (ISAC). } \\
\text { Process innovation (PI). }\end{array}$ \\
\hline Frameworks & $\begin{array}{l}\text { Strategic options development and analysis } \\
\text { (SODA). } \\
\text { Capability maturity model (CMM). }\end{array}$ \\
\hline
\end{tabular}

methodologies and affirm that they do not use any ISDM in practice (Fitzgerald, 1998; Avison \& Fitzgerald, 2003).

There are few studies in the literature about the use of ISDM. In a survey conducted by (Wynekoop \& Russo, 1997) regarding ISDM usage studies, it was found that only 19 papers addressed the issue. The same view has been shared and reported by (Iivari \& Mansari, 1998) as well as by (Huisman, 2003). In addition, (Huisman \& Iivari, 2001) added that most of these studies have been published during the 1980s and 1990s, and that the vast majority of ISDM studies were undertaken to address the experience of developed countries (Rahim \& Seyal, 1998). A review of literature shows that there is insufficient empirical research on ISDM adoption. A survey of prior studies of ISDM adoption is depicted in Table 2. The table shows clear differences between the number of studies of ISDM adoption that have been undertaken in developed and third/developing countries. As illustrated, none has been conducted in the UAE.

\section{Methodology}

This study was conducted using four research methodologies: survey, Interviews, Delphi method, and Case study. Survey mode of enquiry and interviews were employed to obtain data beyond the physical vision of the researcher in order to provide insights into ISDM adoption practices (112 surveys and 16 semi-structured interviews). Delphi method was used to identify and analyze the variables that contribute to effective evaluation and selection of ISDM (128 participation). The research model was developed using a combination of Delphi, and Analytic Hierarchy Process (AHP) techniques aiming to assist IS managers to determine which ISDM is most suitable for their organization's IS development. The case study therefore, was a supplementary research
Table 2.

Prior studies of ISDM adoption.

\begin{tabular}{|c|c|}
\hline Developed country & Description \\
\hline Fitzgerald et al. (1999) & $\begin{array}{l}\text { Investigated systems development and } \\
\text { maintenance in the UK. } 57 \% \text { respondents claim } \\
\text { to be using ISDM. }\end{array}$ \\
\hline Holt (1997) & $\begin{array}{l}\text { Examined software engineering practice in } 50 \\
\text { UK organizations. About } 31 \% \text { of the surveyed } \\
\text { organizations did not use any structured ISDM. }\end{array}$ \\
\hline $\begin{array}{l}\text { Chatzoglou and } \\
\text { Macaulay (1996) }\end{array}$ & $\begin{array}{l}\text { Surveyed the use of ISDM in } 72 \text { IS projects in } \\
\text { the UK. Reported that } 47 \% \text { do not use any ISDM } \\
\text { in IS development. }\end{array}$ \\
\hline $\begin{array}{l}\text { Beynon-Davies and } \\
\text { Williams (2003) }\end{array}$ & $\begin{array}{l}\text { Examined the adoption of ISDM in two } \\
\text { organizations in UK. The study utilized Dynamic } \\
\text { Systems Development Method (DSDM) to } \\
\text { explain some of the key features of the ISDM } \\
\text { adoption processes. }\end{array}$ \\
\hline Venableand Lim (2002) & $\begin{array}{l}\text { Surveyed consulting organizations in Austria that } \\
\text { develop web information systems (WIS). } 67 \% \\
\text { use a type of methodology and about } 10 \% \text { use } \\
\text { WISDM to guide their WIS development } \\
\text { activities. }\end{array}$ \\
\hline Russo et al. (1996) & $\begin{array}{l}\text { Surveyed the use of ISDM in } 92 \text { US } \\
\text { organizations. } 6 \% \text { of the organizations claim that } \\
\text { they always use ISDM. }\end{array}$ \\
\hline Rouse et al. (1995) & $\begin{array}{l}\text { Presented a comparison of ISDM adoption } \\
\text { between Australian and US organizations. The } \\
\text { adoption rate among Australian organizations } \\
\text { found to be slower than that of US organizations }\end{array}$ \\
\hline $\begin{array}{l}\text { Iivari and Maansaari } \\
\text { (1998) }\end{array}$ & $\begin{array}{l}\text { Investigated the use of ISDM in } 44 \text { CASE user } \\
\text { organizations in Finland. Results indicate } \\
\text { considerable problems in adopting the } \\
\text { Object-Oriented methodologies. }\end{array}$ \\
\hline Fitzgerald (1998) & $\begin{array}{l}\text { Examined ISDM usage across organizations in } \\
\text { Ireland. Only } 6 \% \text { of the respondent reported } \\
\text { using ISDM rigorously. }\end{array}$ \\
\hline Developing country & Description. \\
\hline $\begin{array}{l}\text { Huisman and Iivari } \\
\text { (2001; 2002a; 2002b; } \\
\text { 2003a; 2003b; 2003c; } \\
\text { 2006) }\end{array}$ & $\begin{array}{l}\text { Conducted a comprehensive analysis of ISDM } \\
\text { adoption and deployment in South Africa } \\
\text { involving } 83 \text { organizations, } 234 \text { developers, } \\
\text { and } 73 \text { IS managers. }\end{array}$ \\
\hline Rahim et al. (1998) & $\begin{array}{l}\text { Investigated ISDM adoption in public and } \\
\text { private sectors in Brunei Darussalam. Nine } \\
\text { different ISDM reported to be used by the } \\
\text { surveyed organizations. }\end{array}$ \\
\hline $\begin{array}{l}\text { Selamat et al. (1994) } \\
\text { (cited from Rahim et } \\
\text { al., 1998) }\end{array}$ & $\begin{array}{l}\text { Studied CASE tools usage and associated ISDM } \\
\text { in } 40 \text { Malaysian organizations. SSADM reported } \\
\text { to be used by } 8 \% \text { of the surveyed organizations. }\end{array}$ \\
\hline
\end{tabular}

methodology to customize, quantify, and examine the usefulness of the model.

The main objective of the study was to describe the information system environment, the activities performed, and the use of system development methodologies in IS departments in the surveyed organizations within the federal higher education sector, as well as to develop a suitable model for ISDM adoption using two decision-making tools: Delphi technique, and AHP. The model was designed to detect the most appropriate choice among various alternative ISDM. The research sought to resolve the fol- 
lowing three main research questions:

Q1. What is the current status of ISDM practices in the federal higher education sector in the UAE?

Q2. What are the critical variables and their level of importance in evaluating and selecting the most suitable ISD methodology?

Q3. What is the requisite model for ISDM adoption to assist organizations to evaluate and select the most appropriate ISD methodology for their software development activities?

The results of the study provide three main contributions. First, the survey stage of the study reported important information for both the research community and to practitioners. For the research community not much is known about the use of ISDM in developing countries. Far less is known about their use in the UAE and its federal higher education system. For practitioners, this research could assist them in changing or improveing their current systems development practice. One of the key quality control requirements is to employ a formalized information system development process (Fitzgerald, 1998; Huisman, 2003).

Secondly, on the conceptual side, the study shows how two well-known decision-making approaches, Delphi technique, and AHP, could be combined effectively to develop an ISDM decision model. Initially, Delphi technique was suitably employed to analyze and produce reliable variables for decision making. AHP was subsequently employed for model development and for detailed analyses of these variables. On the application side, the study shows how Delphi technique and AHP could be used to develop a requisite group model of ISDM adoption for a large organization in selecting the most suitable ISDM.

Third, the models were developed as a decision support tool. With user friendly software, decision-makers may improve their decision-making processes by running sensitivity analyses, applying the models based on their available information, intuition, and experience, visualizing their decision outcomes, and modifying the models to other relevant issues or scenarios.

Generally, the ISDM adoption model was developed starting from a conceptual model using data from Delphi technique and respondents' perceptions, and then evolved to a user friendly model that can be put to practical use for decision-making in an organization. The case study was employed in order to customize the generic model to fit specific case study using real information and perceptions.

\section{Findings, Data Analaysis, and Discussion}

\section{Current Status of ISDM Practices (Research Question 1)}

The results of the study indicate that the information systems adopted by federal higher education institutions in the UAE are operated in a multi-platform environment, supported by multiple operating systems, using both local and wide area networks, and supporting a variety of development and programming languages. It is worth noting that certain hardware and software platforms, including PCs (computing terminals), Oracle (software), UNIX and Windows (operating systems), and local area networks based environments are the most dominant among federal higher education UAE institutions.

In relation to the activities of IS departments in the responding organizations, the findings reveal that the IS departments spend $62 \%$ of their time on system support and maintenance, $11 \%$ of their time on IS project outsourcing, $17 \%$ on the development of new in-house IS, and $10 \%$ on the customization and integration of commercial packages.

In relation to ISDM usage, the data analysis reveals that $8 \%$ of responding organizations adopted ISDM to develop their information systems. Larger IS departments are more likely to adopt ISDM. In addition, the results of the study show that the older the IS department, the more likely it is to adopt ISDM for IS development. Furthermore, in-house methodologies are the most common ISDM in UAE higher education institutions, followed by Oracle Development Methodology; followed by Rapid Development Method and Information Engineering Methodology (IEM).

In relation to the decision-makers of ISDM adoption, the findings of the empirical survey reveal that a large percentage of the respondents indicate that the decision to adopt ISDM is undertaken by IS managers.

This suggests that IS managers are the key decision makers for ISDM adoption. In addition, the ISDM training provided by organizations to their developers largely relies on in-house trainers followed by external trainers, external institutes, or self-training. Furthermore, an important finding of the empirical survey indicates that the trend of ISDM adoption among the examined organizations will increase over time.

The empirical survey tested a number of variables to examine the extent to which these variables affect ISDM adoption. Nine variables were empirically tested including type of organization, business activity, organization size, IS department size, age of IS department, knowledge barrier, relative advantage, complexity, and compatibility. The findings of the survey reveal that a significant relationship is lacking between type of organization and ISDM adoption, and between complexity and ISDM adoption. However, the remaining seven variables were found to have some relationship with ISDM adoption and the degree of the impact of these variables varies from one variable to other.

\section{Variables and Their Level of Importance (Research Question 2)}

The overall aim of the second empirical stage was to determine and analyze the variables that contribute to effective ISDM adoption. Judgments were solicited from a group of experts in a sequence of successive rounds (Dalkey, 1969). A questionnaire containing 30 variables obtained from the literature regarding the ISDM adoption (evaluation and selection) was sent to 370 prospective panel members.

The potential members were IT/IS managers. In the first round of Delphi method, potential members were asked to rate the level of importance of each of the ISDM adoption variables, and identify more variables that they think are important for the study. The received responses were compiled and consolidated, and a final list of 40 variables was produced. The same procedure was followed for each successive round. Three rounds of Delphi surveys were performed to achieve consensus. Data from the three iterations of the questionnaire were collected during July through September 2009. The analyses of each of the 40 variables were accomplished employing SPSS software. The statistical Median (MD), Quartile One (Q1), Quartile Three (Q3), and Interquartile Range (IQR) were employed to identify the critical ISDM adoption variable, measure level of importance of these variables, and to assess group consensus about these variables. The Delphi process provided three important categories of information about ISDM adoption variables including assent, consensus, and level of importance. 
A group rating of assent for each of the 40 ISDM adoption variables was driven using a Likert five-value scale $(0,1,2,3$, 4). That is, to eliminate variables considered not applicable or not important, a median criterion of less than 2.0 was selected. All remaining variables with a 2.0 median or higher were therefore included in the list of accepted variables (i.e., 4 = Very Important, 3 = Moderately Important, 2 = Somewhat Important). The results obtained indicate that the median of the 40 variables included in the Delphi research questionnaire revealed that none of the variables fell below the criterion of 2.0. Therefore, the Delphi study provided a confirmed group of 40 ISDM adoption variables that can be used for ISDM evaluation and selection as shown in Table 3.

Perceived Relative Advantage: This is the key variable that drives an organization to adopt ISDM or any technology. Relative advantages are perceived benefits gained from ISDM usage. In general, expected advantages from ISDM use may include better end product, better development process, standardizing system development process, increasing productivity and quality, better system documentation, etc. (Rogers, 1995; Fitzgerald, 1998; Huisman \& Iivari, 2002; Avison \& Fitzgerald, 2006).

ISDM Properties and Features: This directly influences new ISDM adoption. ISDM feature variables include: ISDM costs, ability to customize ISDM on a project-by-project basis, simple to understand and teach, compatibility with existing systems, techniques utilized within ISDM, observability, trialability, and flexibility (Rogers, 1995; Fitzgerald, 1998; Huisman \& Iivari, 2002; Avison \& Fitzgerald, 2006).

Organizational Environment: These should be suitable for accommodating new ISDM in order to obtain advantages from ISDM use. Organizational issues include: sufficient resources and facilities, management support, developer acceptance, developer experience, and developer skill and knowledge (Fitzgerald and Russo, 2002; Huisman \& Iivari, 2003; Avison \& Fitzgerald, 2006).

Table 3.

ISDM adoption variables.

\begin{tabular}{lll}
\hline $\begin{array}{l}\text { Relative Advantage } \\
\text { Variables }\end{array}$ & $\begin{array}{l}\text { ISDM Properties and } \\
\text { Features Variables }\end{array}$ & $\begin{array}{l}\text { Organizational } \\
\text { Environment Variables }\end{array}$ \\
\hline Better end product & Cost of ISDM & Resources \\
Better devel. process & Customizable & Management support \\
Standardizing & Compatibility & Developer acceptance \\
Productivity & Techniques & Developer experience \\
Quality & Rules & Developer skills \\
Documentation & Scope & Customer acceptance \\
Speed of development & Problem analysis & Customer satisfaction \\
Schedule and budget & IS project management & \\
Speed of development & Communication & \\
Maintainable & Simplicity & \\
Learning & Development Model & \\
Acceptance & Observability & \\
Requirements & Trialability & \\
Configuration control & Reductionist & \\
ISO compliance & Flexibility & \\
Reduce risk & Supplier Support & \\
& Tools support & \\
\hline
\end{tabular}

\section{Requisite Model of ISDM Adoption (Research Question 3)}

The third empirical stage of this study focused on developing a general ISDM adoption decision model based on the variables obtained from the Delphi technique. In addition, this stage concentrated on adjusting and quantifying the general ISDM model based on the selected organization employees' perspective in order to examine the practicality of the model. The design of the ISDM adoption model allows decision-makers to decide which ISDM is more appropriate for their IS department. The model developed in this study consists of four levels. The top level represents the goal/objective of selecting suitable ISDM in order to adequately meet the organization requirements, needs, and preferences. The last level is represented by the ISDM alternative. The second and third levels constitute the main variables and sub variables respectively, which affect the decision to select the appropriate ISDM. These variables, affecting the choice of ISDM, were determined from the literature review and subsequently evaluated and analyzed using Delphi technique. The model is simple to use and the computations can be run using available specialized software such as "Expert Choice".

AHP technique was employed for ISDM evaluation and selection for the case study. The model development comprised three stages: structuring the problem/objective, driving information and values, and evaluation.

The first stage was to identify the objectives that the case study is aiming to achieve. Then, all potential ISDM alternatives were identified for evaluation under a set of specific variables. The five ISDM alternatives perceived to fulfill the needs of the IS department of the case study objective are: Dynamic Systems Development Method (DSDM), Extreme Programming (XP), in-house methodology, Structured System Analysis and Design Methodology (SSADM) and Rational Unified Process (RUP). Each of these ISDM alternatives was evaluated using the same variables. High level variables consisted of relative advantages, features of ISDM, and case study environments. Each high level variable was sub-divided into low level variables, including specific issues detailed from the main variables.

During the second stage, respondents were asked to weigh the level of importance (i.e. a pair-wise comparison judgment) of each criterion and then score all the alternatives against the specified criteria.

The last stage evaluated the alternatives and conducted sensitivity analysis using the ExpertChoice software. Results from the AHP analysis revealed that the preferred ISDM was in-house methodology and the second alternative was RUP.

In effect, the proposed model of ISDM adoption helps decision-makers to increase their level of understanding and solving of problems, compares the rational results with their intuition, detects possible relevant reasons behind objective results, and allows them to improve their decision-making by adjusting weighting and scoring, and conducting sensitivity analyses.

\section{Conclusion}

This research "ISDM Adoption within the Context of a Developing Country" combines three study areas of information systems: information system development methodologies adoption, Delphi technique, and Analytical Hierarchy Process. The study was conducted using four research methodologies: survey research, Interviews, Delphi method and a case study in large federal higher education institutions in the UAE. The data were 
collected from three empirical stages using three data collection methods (i.e. questionnaires, interviews, and documents).

ISDM are perceived to play a critical role in information system development processes. However, the findings of this study indicate that a very small percentage of the examined IS units utilize ISDM for their IS development activities, which means that federal higher education institutions in the UAE have a long way to go before achieving standardization of information system development processes. The study has raised the importance of studying the practice of ISDM in a developing country and within the federal higher education sector in specific. It is clear that even though a wide range of published ISDM are cited in the IS literature, their adoption is quite low within the federal higher education sector in the UAE. This study further found that the adoption of ISDM is related with the nature of business activities. For example, IS units supporting students' registrationsused a somewhat more structured ISDM approach than IS units supporting Purchasing and Procurement.

Furthermore, a clear difference in ISDM adoption was noticed between different size IS departments. Such a difference was also noted between mature and novice organizations. Older universities seemed to adopt a more structured ISDM than newer ones. Interestingly, most of the factors believed to be a reason for not using ISDM could not be supported by the survey results. However, lack of understanding and lack of appropriate knowledge of ISDM concepts and principles and their implications is a significant barrier to adoption; successful adoption exists only if those concerned have a full understanding of the ISDM. Surprisingly, the majority of respondents disagreed with the statement that ISDM are too complex or hard to use. This could be explained due to the fact that most of the surveyed IS units are not using ISDM. Thus, they might not have a clear picture of its complexity. It is, however, expected that the growth of popular ISDM is likely to increase with time.

The proposed model of ISDM adoption based on Delphi technique and AHP analysis demonstrated an easy procedure to select the best alternatives from various conflicting variables. Using the AHP tool supported by "ExpertChoice" software may help IS practitioners evaluate ISDM alternatives more efficiently and effectively, compared to the traditional method.

First, AHP is a suitable tool for ISDM evaluation. Second, AHP software applications are inexpensive and available in the market. Third, the software applications are easy to learn and use within a short time. Fourth, outcomes from an AHP analysis can be compared with the intuition or experience of decision-makers and provide insight into differences. Fifth, AHP allows decisionmakers to conduct sensitivity analysis to test for different scenarios and conditions of problems. Sixth, the proposed model mitigates conflicts and promotes consensus of group decision-making by identifying reasons of outcomes. Finally, an AHP analysis is applicable to other issues in regard to choice selection or alternative evaluations.

This study has examined a systematic way of assessing alternatives of ISDM, which is a complex and controversial issue. It has endorsed the idea that good decision-making should focus on objectives and not on alternatives. It has drawn attention to the use of the Delphi technique and Analytic Hierarchy Process (AHP) in evaluating ISDM alternatives in a complex decisionmaking process. The purpose of the ISDM adoption decision model was to find a better way to assess ISDM alternatives. Both Delphi technique and AHP have never been used before to evaluate ISDM in order to select the appropriate ISD methodology for organizations. The contribution of this study is not to do just anything that has never been done before, but something that is important and better. In this case, it is to apply suitable techniques that are more effective and can produce better results.

\section{Future Research}

The knowledge gained from conducting the research relating to ISDM adoption, Delphi technique, and AHP technique areas can be further developed and expanded to deal with many prospects. This research intended to investigate ISDM adoption based on the views of senior IS managers who were in charge of IT/IS departments within the surveyed organizations. Therefore, the investigation was limited to the UAE and the examined federal higher education sectorin terms of ISDM use, techniques, IS environment, trend of ISDM adoption, barrier, etc. The study did not make an effort to investigate the ISDM practices from the IS developer point of view. Accordingly, future studies should focus on the views of those individual IS developers who work in information system development projects. Their opinions could differ considerably from that of their senior IS managers. Future studies on ISDM practices within the context of developing countries are highly recommended to manifest the status of ISDM practices in these countries.

In terms of Decision Making, the proposed model using Delphi technique and AHP technique is suitable for evaluation and selection. However, the best selection does not always guarantee successful deployment or implementation, nor ensure a good return on investment. Therefore, this research can be expanded by using other decision-making techniques such as System dynamics (SD). Research combining the three areas of Delphi technique, AHP and SD is a fruitful area to be developed.

\section{REFERENCES}

Avison, D. E. \& Fitzgerald, G. (2006). Information systems development: Methodologies, techniques \& tools. Boston, MA: McGrawHill.

Beynon-Davies, P. (1998). Information systems development. London: Macmillan.

Beynon-Davies, P. \& Williams, D. M. (2003). The diffusion of information system development methods. Journal of Strategic Information System, 12, 29-46. doi:10.1016/S0963-8687(02)00033-1

Charvat, J. (2003). The project management methodologies: Selecting, implementing and supporting methodologies and processes for projects. Hoboken, NJ: John Wiley \& Sons Inc.

Fitzgerald, B., \& Russo, L. (2002). Information system development: Method in action. Boston, MA: McGraw-Hill Education.

Fitzgerald, B. (1998). An empirical investigation into the adoption of system development methodologies. Information and Management, 34, 317-328. doi:10.1016/S0378-7206(98)00072-X

Huisman, H. M., \& Iivari, J. (2003). Adaptation and the deployment of systems development methodologies. Proceedings of the International Conference on Computer, Communication and Control Technologies and the 9th International Conference on Information Systems Analysis and Synthesis, Tampa, 1 July-2 August 2003.

Huisman, M., \& Iivari, J. (2001). The relationship between organisational culture and the deployment of systems development methodologies. Lecture Notes in Computer Science, 2068, 234-250.

Huisman, M., \& Iivari, J. (2002). The individual deployment of systems development methodologies. Lecture Notes in Computer Science, 2348, 134-150.

Huisman, M., \& Iivari, J. (2006). Deployment of systems development methodologies: Perceptual congruence between IS managers and systems developer. Information \& Management, 43, 29-49. $\underline{\text { doi:10.1016/j.im.2005.01.005 }}$ 


\section{A. MARKS}

Iivari, J., \& Huisman, M. (2001). The relationship between organisation culture and the deployment of systems development methodologies. Lecture Notes in Computer Science, 2068, 234-250. doi:10.1007/3-540-45341-5_16

Rahim, M., \& Seyal, A. H. (1998). Use of software system development methods. An empirical study in Brunei Darussalam. Informa- tion and Software technology, 39, 949-963.

doi:10.1016/S0950-5849(97)00052-9

Wynekoop, J. L., \& Russo, N. L. (1997). Studying system development methodologies: An examination of research methods. Information Systems Journal, 7, 47-65. doi:10.1046/j.1365-2575.1997.00004.x 